\title{
Grassroots Animation in the Digital Age
}

\author{
Zhang Sancong \\ Jingdezhen University of ceramics Jiangxi 333403
}

Keywords: digital age; grassroots; grassroots animation; new media

Abstract: At the end of the last century, the world began to enter the digital age. The blowout development of digital information technology and the third industry promoted the prosperity of contemporary animation art. The original grassroots animation with unique and diverse forms has attracted worldwide attention, and gained great development through the Internet and new media technology. Grassroots animation is not a unique product of the digital age, but it has gained an explosive growth in the digital age. This paper tries to analyze the prevalence of grassroots animation in the digital age from many aspects.

\section{The Digital Age and the Grassroots Animation}

The digital age is actually the pronoun of the digital information age. At the end of the last century, with the popularization of computer technology and the rapid development of the Internet, the world began to enter the digital age. The development of digital information technology and the blowout of the third industry promoted the prosperity of contemporary animation art. In November 26, 2013, the "animation Blue Book: China Animation Industry Development Report (2013)", CO sponsored by the literature press of Beijing Film Academy and the Academy of Social Sciences, was published in Beijing. The blue book points out: in recent years, 3D animation has become popular and gradually occupied the theater animation market. However, in the Internet and new media, the original grass root animation with unique and diverse forms has also developed a new stage. With the development of the Internet and new media technology, the original grass root animation presents the growth momentum, in the network medium. The body has been fully displayed.

The word "grass roots" comes from the English word "grassroots". Its meaning is: grass roots, grass-roots, grass-roots people; grass-roots, grass-roots, rural. In the contemporary society, we often see the group called "Cao Gen" in the newspaper and on the Internet, such as Cao Gen star, Cao Gen hero, Cao Gen writer, Cao Gen photography and so on. "Cao Gen" is regarded as a word against authority, elite, profession and power, and Cao Gen group comes from the masses of civilians, he They are neither the elite nor the authority. They are numerous, but their forces are very weak. They are often non mainstream, non professional, lack of discourse power and dominance, and are neglected for most of the time.

Grass root animation, from the literal point, we can understand the two meanings: on the one hand, it refers to the animation of the social grass root force creation, on the other hand refers to the animation of the life and life of the social grass roots. The grass roots animation discussed in this article mainly refers to the first category, that is, all kinds of animated works created by grassroots forces. The "grass root" defines more than one state, more is a spirit, a kind of feelings, the 
grassroots animation creators adhere to their ideals and standards, not attached to any interests or values, adhere to independent thinking, independent creation, relative to the authority and animation enterprises, grassroots animation creators are lonely And the weak, but their original animation works on the Internet from time to time, subverting people's impression of the era of domestic animation, but also make up for the single, poor interaction of cinema and TV animation.

\section{The Cause of the Prevalence of Grassroots Animation in the Digital Age}

Grass root animation is not a product of the digital age, but grass root animation has gained an explosive growth in the digital age, and has aroused unprecedented attention. This paper tries to analyze the reasons for its popularity in the following aspects.

\subsection{The development and popularization of the animation technology in the digital age}

Animation is a highly integrated art of technology and art. Throughout the history of animation development, from its emergence to development, every technological change has a far-reaching impact on the creation of animation. At the beginning, the development of real film technology, the development of the technology of continuous shooting, film printing and continuous projection technology contributed to the emergence of animation. Later, the technology of sound film and color technology make animation more complete and become a mature art type. For a long time, animation creation is the exclusive of professional organizations, because it requires a lot of technology and capital input. In order to create a two-dimensional hand drawn animation film, it is necessary for a large number of professionals to draw tens of thousands of pictures. The draft, line drawing, and color need to be finished manually, then one is taken, and the composing and dubbing is finally made into animated films. Barriers to technology and capital make it difficult for grassroots groups to create an animation independently. In the 60s of last century, the development of digital technology and computer graphics became more and more mature. Computer aided design began to be applied to animation creation, which opened the door of the digital animation era. With the advent of the digital age, the powerful and compact microcomputers are popularized in individual users, especially the rapid development of computer graphics. A large number of digital animation software has been developed. These software integrates powerful animation function, and an animated short film is only with the help of computer and animation. The software can be done. For example, Yang Yu, the author of "hit a big watermelon", he studied medical specialty at University, and began to learn animation related knowledge about the hobby of animation. After three years at home, a person completed his animated maiden works by a computer. The development and popularization of animation technology in the digital age makes the barriers not exist in front of the grass-roots group. With the love of animation, many individuals, even the animated enthusiasts without professional training, can be among the creation of animation.

\subsection{The prevalence of grassroots culture in the digital era}

While the digital age brings us technical innovation, it is also changing people's ideas and ideas. The ideas of equality, sharing and participation in the network society are gradually accepted by the masses, forming a grassroots cultural trend. In 2006, the American "times" weekly selected the person of the year. On that issue, the magazine cover was not a portrait of a well-known politician and social elite, but a computer. A big word "You" was displayed on the screen. "Yes, you are the annual figure of the year." You control the information age and welcome to your world. "You" refers to the large number of netizens who are facing the computer everyday. Before, history is only the Autobiography of great men, a few elite and power and power have shaped the collective destiny of 
the masses. Now this phenomenon has been severely damaged, and the grassroots forces actively and actively participate in the construction of the "digital democratic society". People around the world are linked together through the Internet to the elite culture and Guan Fangwen. The impact is initiated. In this environment, communication activities have become increasingly grass-roots, civilian, the popular "Britain's" "Britain's" "Super Girls" and "British" popular show has created Susan's mother, Jane Zhang and other grassroots stars, overnight culture in the world is popular in the world.

The prevalence of grass-roots culture puts equal opportunities in front of young people who are difficult to obtain opportunities under the original system. This is a bold challenge to institutional arrangements and seniority. Grass roots culture draws the distance between the common people and the mainstream, and fills the gap between the two. When people are tired of the sleepy animations on TV, the grass roots animation begins to walk into people's vision. Many excellent grassroots animation writers think independently and independently. They do not rely on a certain value or gain a certain benefit. Their work has a strong flavor of the times and personal features. The current public aesthetic taste, a lot of excellent grassroots animation works, once released, in the unprecedented speed in the network media spread, showing a strong vitality.

\subsection{The acquisition of the discourse right of grassroots groups}

The new media in the digital age has given the grassroots group an unprecedented right to speak. The new media is a relative concept. The new media in the digital age is a new media form developed after the traditional media, such as newspapers, radio and television. Its typical features are the use of digital technology, network technology, mobile technology, Internet, communication network, satellite channels, and computers, mobile phones and digital TV sets. And other terminals, to provide users with information and entertainment services in the form of communication and form of media, that is, digital media.

The digital media has many characteristics, such as unlimited openness, wide spread, rapidity of communication, diversity of communication, equality of communication, and so on. In this new media platform, people have subverted the order, the aesthetic standards of elite, and entered a comprehensive and shared communication era. In the past, grassroots animation was difficult to spread in TV and cinema because of the influence and restriction of various cultural systems.

\subsection{The diversified demand for animation in the digital era}

The digital age has brought great changes to our life. The digital devices, such as smart phones, tablets, digital TV, PC and other digital devices are widely used in the daily life. The digital life brings new digital communication methods. This also brings out the unique animation demand of the digital age, and the grassroots animation group is flexible adaptation. The characteristics make it a useful supplement to the animation industry, and soon make up for the demand for new animation in the digital age.

For example, now our common network expression animation is a graphical language used by both parties when communicating with the Internet, using exaggerated and funny animated images to simulate and substitute the realistic expression, so that the ice cold communication face to the screen becomes vivid and vivid. Facial animation is different from the traditional animation. It usually has only a few seconds to convey emotion through the expression of the role or the body performance. Without the plot, it is often a fragmented language, but the user can freely combine to produce a new meaning, so as to get a new entertainment experience. Compared with animated short films, facial animation is not very demanding of animation technology and artistic attainments, so it has more popular participation, and soon become the test field of the grass root animation 
creators. For example, the famous expression animated "rabbit" on the Internet, the animated author named Wang Maomao, in 2007, she was still an unknown student at Communication University of China. Rabbit was an image of her usual writing and painting. She drew the image of the rabbit with a simple line, and the innocence of her expression. And indifferent, the action is exaggerated and funny. The image of tuskey resonated with the psychology of netizens' entertainment and revelry, and became popular at the explosive speed on the Internet. Therefore, it is widely used and forwarded as an example of the extensive influence of grassroots animation.

\subsection{The flourishing development of animation education in the digital era}

With the arrival of the digital age, the animation ushered in a new prosperity period, the foreign animation upsurge swept the country, and the animation education in China has expanded rapidly under the influence of this kind of animation upsurge. The animation education in the digital age is more specialized and multi-layered, which reduces the threshold of learning animation knowledge, and makes many grassroots people who love animation become the beneficiaries. In the last century, colleges and universities in the whole country only set up animation majors in Beijing Film Academy. After 2000, colleges and universities began to set up relevant majors, and enrollment increased rapidly. Professor Xiao Yongliang of Beijing Normal University in the current situation of Chinese animation education pointed out: "according to the Ministry of education, according to the incomplete statistics in 2007, there are 656 colleges and universities in China to set up animation majors (small caliber Statistics). In 2007, there are 8634 graduates, 35000 students are enrolled, and 70000 people are in the school. Because the current animation related to a lot of major, if the large size of statistics is more, in 2007, the National College animation class 90 thousand graduates, enrollment of 200 thousand people, at the time of 580 thousand people in school. According to the current development trend, by 2012, colleges and universities can prepare for the animation industry nearly 600 thousand, each year, there will be about 100000 related professional graduates to the society. After more than ten years of development, the number of animation professionals trained by higher education has reached hundreds of thousands, and it has become the main force in the development of animation industry.

At the same time, the animation education of colleges and universities is flourishing, and many training institutions are growing like mushrooms, such as the Mars age, the crystal stone, the perfect power and so on. These training institutions have no threshold, short learning cycle, and few constraints, so it is very pertinent to meet the demand of the general public on the professional skills of animation, and become a supplement to the animation education in Colleges and universities.

\section{Conclusion}

The digital age brings new technology and communication way to people's life, and has a profound influence on the creation of animation. The domestic animation creation has entered a new period of prosperity after the trough. The original spirit of the grass root animation is unique in form and content, caters to the aesthetic taste of the public. The digital age provides a suitable soil for its growth. Thus, it has gained a great increase in recent years, and has become a new supplement to the animation industry. It is important to note that although several excellent grassroots animation works have been successful, the whole grass root animation creation is still in the spontaneous fumbling stage, and many animation grass roots are facing the problems of survival and development. With the popularity of mobile media, such as TV, network and today's mobile phones and mobile TV, the propagation of grass root animation will get more space and development direction. Encouraging the support of original grassroots animation on policy and capital will also become an important topic for China's animation industry policy in the future. 


\section{Acknowledgements}

Fund: Jiangxi provincial art and science planning project "Research on grassroots animation in the digital age" (Project No.: YG2013139).

\section{References}

[1] Xiao Yong Liang. Analysis of the current situation of Chinese animation education [J] Journal of Beijing Union University humanities and Social Sciences Edition 2011 Volume 93 issue

[2] Liu Haibo Dai Yi. Collision of grassroots art and mainstream culture in the post technological age [J] Tianya 2010 sixth issue

[3] Yang Dongrun. [J] in the new media, [J], art life, third. 